\title{
Situación actual de la donación-trasplante de órganos y tejidos en Andalucía
}

\section{Current situation of donation organ and tissue transplant in Andalusia}

\author{
M. Alonso Gil \\ Coordinador Autonómico \\ de Trasplantes de \\ Andalucía. Servicio \\ Andaluz de Salud \\ Correspondencia: \\ Manuel Alonso Gil \\ E-mail: manuel.alonso.sspa@ \\ juntadeandalucia.es
}

Fecha de recepción: 19.MAY.2015

Fecha de aceptación: 25.MAY.2015

\section{Resumen}

La situación actual de los programas de trasplantes de Andalucía constituye un fiel exponente del grado de modernidad, desarrollo y avance social experimentado en los últimos años. En efecto, debemos estar orgullosos de vivir en una comunidad que ocupa un lugar destacado en todo el mundo en donación-trasplante, a gran distancia de los países avanzados de nuestro entorno, incluidos los míticos EE.UU. La probabilidad de recibir un trasplante en nuestro sistema sanitario público en caso de necesitarlo es doble que en el resto de los países desarrollados. Se describe el trabajo desplegado en los últimos 25 años, que ha hecho que Andalucía pase de estar en el "furgón de cola" a ocupar un consolidado lugar de liderazgo y ser referente de un país, España, que es el primero del mundo en donación y trasplantes de órganos de forma consecutiva en los últimos 23 años.

Palabras clave: Donante. Médico forense. Trasplante. Juez.

\section{Abstract}

The current situation of the Andalusian transplant programs is a valuable example of the degree of modernity, development and social progress made in recent years. Indeed, we must be proud of living in a region that leads worldwide the donor-transplantation rates, far better than other develop countries, including the mythical USA. In Andalucia, the chances of receiving an organ transplant is twice than in other developed countries. In this article we describe the organ transplant organisation in Andalucia over the last 25 years. Andalusia has become one of the most important regions in Spain, country which leads the organ donation transplant rates worldwide in the past 23 years.

Key words: Donor. Medical examiner. Transplant. Judge.

\section{Introducción}

Es preciso recordar que la era de los trasplantes de órganos comenzó en el año 1954 en Boston (EE.UU.), cuando tuvo lugar el primer trasplante renal con éxito entre hermanos gemelos univitelinos. En España, la historia del trasplante de órganos comienza 10 años más tarde, en 1964, cuando casi a la vez se llevan a cabo los primeros trasplantes renales en el Hospital Clínico de Barcelona y la Fundación Jiménez Díaz de Madrid. En Andalucía es el Hospital Virgen del Rocío, de Sevilla, el que inicia nuestra era de los trasplantes de órganos realizando en 1978 el primer trasplante renal en nuestra Comunidad, con un retraso de 14 años con respecto a España.
El resto de los programas de trasplantes de órganos sólidos andaluces han iniciado su historia en el Hospital Reina Sofía de Córdoba: trasplante cardíaco en 1986, trasplante de páncreas en 1988, trasplante hepático en 1989 y trasplante de pulmón en el año 1993.

Han pasado, pues, 36 años desde que se inició esta actividad en Andalucía y podemos decir con plena satisfacción que el trasplante ha pasado de ser una técnica casi experimental y mágica a constituir una realidad terapéutica perfectamente consolidada que, sin lugar a dudas, forma parte de nuestro actual grado de desarrollo.

Concretamente, podemos citar algunas cifras de los últimos años: en 1991, año en que se crea la 


\begin{tabular}{|c|c|c|c|c|c|c|c|}
\hline & 1991 & 1995 & 2000 & 2005 & 2010 & 2014 & Dif. \% 91/14 \\
\hline Donantes de órganos & 93 & 141 & 200 & 259 & 261 & 315 & $+339 \%$ \\
\hline $\begin{array}{l}\text { Tasas de donantes de órganos } \\
\text { por millón de población }\end{array}$ & 13,4 & 19,3 & 27,2 & 33 & 31,2 & 37,5 & $+280 \%$ \\
\hline Trasplantes de riñón & 161 & 251 & 295 & 330 & 330 & 453 & \\
\hline Trasplantes de hígado & 36 & 75 & 123 & 161 & 168 & 205 & \\
\hline Trasplantes de corazón & 43 & 43 & 37 & 37 & 26 & 34 & \\
\hline Trasplantes de pulmón & - & 10 & 19 & 20 & 25 & 26 & \\
\hline Trasplantes de páncreas & 3 & 4 & 17 & 30 & 22 & 18 & \\
\hline Total trasplantes órganos & 243 & 383 & 491 & 578 & 571 & 736 & $+302 \%$ \\
\hline
\end{tabular}

Coordinación Autonómica de Trasplantes de Andalucía, se consiguieron 93 donantes de órganos y se realizaron 288 trasplantes de órganos sólidos, y en 2013 se llevaron a cabo 686 trasplantes gracias a la generosidad de 297 donantes (Tabla 1). A fecha de 31 de diciembre de 2013, ya llevábamos 14.184 trasplantes de órganos: 9.007 enfermos renales trasplantados, 3.398 trasplantes hepáticos, 999 trasplantes cardiacos, 443 de pulmón y 337 de páncreas (Tabla 2). Además, se han realizado más de 35.000 implantes de diversos tejidos (córneas, tejido óseo y tendinoso, válvulas cardiacas, etc.) y de progenitores hematopoyéticos (que incluye a los de médula ósea). Por consiguiente, son ya muchos los andaluces que se han beneficiado de los programas de trasplantes, salvando sus vidas o mejorando la calidad de las mismas. Las cifras son elocuentes y hablan por sí mismas.

\section{Descenso de los fallecidos en muerte encefálica}

No obstante, la Coordinación Autonómica de Trasplantes de Andalucía ya detectó hace unos años un descenso lento, pero paulatino, de los fallecidos en muerte encefálica (Figura 1 ). Al ya conocido y positivo descenso de la mortalidad vial, se añade el de fallecimientos por accidente vascular cerebral debido, entre otros factores, a un mejor tratamiento de la hipertensión arterial. Además, la limitación de las terapias de soporte vital avanzado en fallecimientos inevitables (prácticas muy extendidas en el norte de Europa) es cada vez más frecuente. Esta situación determina una disminución de las donaciones. Por poner el ejemplo de los donantes que fallecen a consecuencia de un accidente de tráfico, decir que han pasado de representar el $40 \%$ a inicios de la década de 1990 al $5 \%$ en el año 2013.

\section{Estrategias alternativas adoptadas}

Es una realidad perfectamente constatada que el donante de órganos es progresivamente más añoso, habiendo pasado la edad media de 35 años en 1991 a 60 en 2014. Así, por ejemplo, el porcentaje de donantes ideales, que son los que tienen entre 16 y 45 años, representan actualmente sólo el 10\% del total, cuando en 1993 significaban el 54\%. Por el contrario, los donantes de 60 o más años han pasado del $6 \%$ en 1993 al 59\% en el pasado año. Este hecho determina que, además de que se vaya incrementando el porcentaje de contraindicaciones médicas de los donantes potenciales con diagnóstico de muerte encefálica, el número de órganos válidos para trasplante por cada donante sea cada vez más bajo, por lo que el descenso de trasplantes es superior al de donantes.

Por todo ello, desde hace años, estamos desarrollando iniciativas para contrarrestar esta situación.

\begin{tabular}{lr}
\hline Trasplante & \\
\hline Riñón & 9.007 \\
Hígado & 3.398 \\
Corazón & 999 \\
Pulmón & 443 \\
Páncreas & 337 \\
Total & 14.184 \\
\hline
\end{tabular}

Tabla 1.

Actividad general del programa de donación-trasplante de órganos en Andalucía desde que se creó la Coordinación Autonómica de Trasplantes. 1991- 2014

Tabla 2.

Trasplantes de órganos realizados en Andalucía desde 1978 hasta el 31-12-2014. 
Figura 1. Evolución de la tasa de muerte encefálica por millón de población, Andalucía 2004-2014.

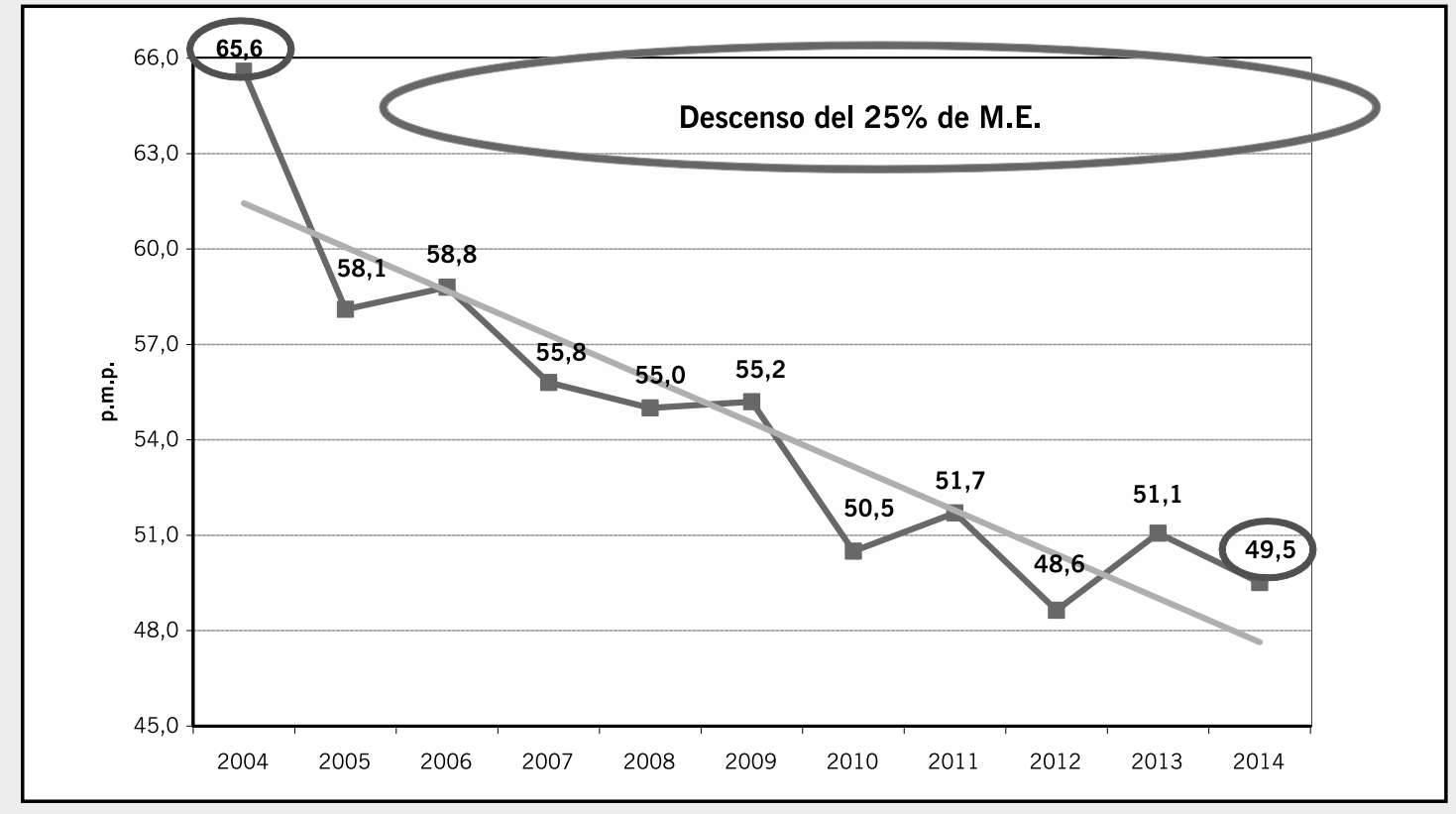

Además de la donación de vivo y el trasplante renal cruzado, se ha impulsado la donación de órganos en casos de fallecimiento por parada cardiorrespiratoria o donación en asistolia. También se ha desarrollado el trasplante birrenal, siendo el Hospital Regional de Málaga el que ha realizado más intervenciones de este tipo en España. Habitualmente, cuando el donante no tiene una edad muy avanzada se trasplanta un riñón a cada receptor, y cuando el donante es muy añoso el trasplante de un solo riñón no garantiza en el receptor el mínimo grado de función renal para abandonar la diálisis. Es entonces, y tras la preceptiva biopsia renal, cuando se implantan los dos riñones en un solo receptor, garantizando el funcionalismo renal. Además, cuando hay receptores adecuados para ello, se realiza el trasplante hepático en dominó, en los que una sola donación de hígado permite realizar dos trasplantes hepáticos.

\section{Equidad, calidad y eficiencia}

Consideramos que no solamente es importante conseguir un elevado número de trasplantes, sino que, además, los trasplantes se deben hacer al menor coste y con la mayor calidad posible. Igualmente es fundamental conseguir la menor variabilidad clínica posible y la máxima equidad. En pleno siglo XXI no es admisible que los diferentes equipos de trasplantes tengan distintos criterios. Además, la disponibilidad de órganos para trasplantes debe ser homogénea y equitativa para los diferentes equipos de trasplantes y población asistida, de tal forma que cualquier andaluz que necesite un trasplante acceda al mismo en igualdad de oportunidades, independientemente de cuál sea su lugar de residencia. Para cumplir las anteriores premisas, la Coordinación Autonómica de Trasplantes, siguiendo la metodología de la gestión por procesos asistenciales, ha desarrollado, junto con los diferentes expertos en la materia, procesos asistenciales integrados de todos los tipos de trasplantes: hígado, corazón, pulmón, páncreas, riñón y, por último, también de tejidos. Las consecuencias de estos procedimientos han sido las siguientes:

- Se han consensuado todos los protocolos de actuación, incluyendo no sólo las indicaciones de trasplantes sino también los criterios de priorización en lista de espera.

- Se han creado y ampliado registros de trasplantes, desapareciendo los registros anteriores que existían en sociedades científicas y centralizándose todos ellos en la Coordinación Autonómica de Trasplantes.

Todo lo anterior ha conducido a un excelente clima de cordialidad entre la Coordinación Autonómica de Trasplantes y todos los equipos de trasplantes, 
anteponiéndose el interés general de Andalucía al particular de cada hospital o provincia, y siendo el enfermo andaluz el principal referente que guía todas las actuaciones, de modo que, a pesar de la homogeneidad de las actuaciones entre los equipos de trasplantes, el paciente pueda solicitar también una segunda opinión.

Que sepamos, no hay ninguna otra comunidad autónoma que tenga establecidas más medidas encaminadas a conseguir la máxima equidad que Andalucía. Como se podrá ver, estas medidas son importantes y rigurosas, lo que sin lugar a dudas debe conducir a la máxima transparencia y, por ende, a una mayor credibilidad del ciudadano en el sistema sanitario público de Andalucía. Esta credibilidad en el sistema de trasplantes es, entre otras cosas, la que facilita e induce a nuestra sociedad a decir Sí a la donación.

\section{Protagonistas de los resultados}

Esta magnífica realidad ha sido posible gracias a la participación y el esfuerzo de una variada gama de protagonistas:

- En primer lugar, y de forma destacada, hay que situar a los propios pacientes y a sus respectivas asociaciones, que fueron los que con su presión y lucha sistemática consiguieron del gobierno español que se promulgara nuestra Ley de Trasplantes en $1979^{1}$, texto normativo excelente ya que sigue con plena vigencia a pesar de los 35 años que han transcurrido desde entonces, que ha sido copiado por otros países y que ha posibilitado que todos los profesionales tengan un marco jurídico seguro para el desarrollo de su actividad. Esta ley ha sido posteriormente desarrollada por diferentes normativas nacionales y autonómicas.

- Mención especial merece el sistema organizativo de los trasplantes ${ }^{2}$, con unos cualificados profesionales como son los coordinadores de trasplantes. Está claro que sin donantes no hay trasplantes. $Y$ para que haya donantes, lo primero, básico y fundamental es que se detecte su existencia. Pues bien, esta es la principal labor del coordinador de trasplantes hospitalario, figura principal de nuestro sistema organizativo de donación-trasplantes.

- Lugar preeminente ocupan los profesionales de los diferentes equipos de trasplantes. En efecto, su dedicación, permanente disponibilidad y gran experiencia determinan no sólo unos excelentes resultados de supervivencia ${ }^{3-6}$, sino también que no se pierda ningún órgano, aunque para ello tengan que trabajar de forma ininterrumpida 24 horas consecutivas, como ya ha ocurrido en distintas ocasiones.

- También es necesario destacar la importante, positiva y callada labor que desempeñan todos los jueces y forenses en todos y cada uno de los procesos donde su autorización es pertinente y preceptiva para proseguir con el proceso de donación. Desde siempre en Andalucía hemos contado con su impecable trabajo y colaboración para que, aunque un cadáver sea judicial, no por ello deje de ser donante. Y no sólo eso, el premio andaluz de periodismo que reconoce cada año la labor de los medios de comunicación en la concienciación de nuestra sociedad a favor de la donación lleva, desde el año 2001, el nombre del que fuera Fiscal Jefe de Tribunal Superior de Justicia de Andalucía, Luis Portero, que después de ser vilmente asesinado por la banda terrorista ETA fue donante de órganos y tejidos. Todo un ejemplo.

- La sociedad desempeña un papel central a través de su respuesta solidaria a la donación. En este sentido es preciso aclarar que hemos avanzado también de forma espectacular $\mathrm{y}$, afortunadamente, podemos decir que la sociedad andaluza es hoy día mucho más proclive a donar que hace unos años. $Y$ es que no resulta razonable pensar que Andalucía era menos solidaria hace 20 años, a principios de los noventa, cuando la negativa a donar era del $40 \%$, que ahora, cuando la tasa está situada en el $15-20 \%$. El progresivo descenso de la negativa a donar, o mejor dicho, el progresivo aumento de la concienciación ciudadana favorable a la donación, obedece claramente a una mejor información de nuestra sociedad andaluza. En esta tarea hay que citar a todos los agentes sociales implicados. Efectivamente, además de todos los recursos aportados por la administración sanitaria y de la labor de difusión de los coordinadores de trasplantes informando de forma periódica y perseverante de los positivos efectos de la generosa acción de donar por diferentes ámbitos (colegios, asociaciones culturales, etc.), otros colectivos contribuyen también de forma notable a esta noble tarea como las distintas asociaciones de enfermos $y$, de una forma muy especial, los medios de comunicación. Mencionar, por otra parte, que nuestra normativa de voluntades anticipadas favorece asimismo la posibilidad de hacerse donante. 
- Por último, dejar de manifiesto el gran apoyo que los diferentes responsables sanitarios y no sanitarios de la Junta de Andalucía han prestado desde siempre a la donación-trasplante de órganos y tejidos.

En los últimos diez años la Red de Coordinación ha ido creciendo y perfeccionándose, adquiriendo una dimensión óptima en el momento actual, lo cual ha facilitado la consecución de estos brillantes resultados. Y ello es debido no sólo al importante crecimiento de la Red de Coordinación, sino también al trabajo desarrollado por los coordinadores de trasplantes hospitalarios dentro y fuera de sus hospitales, actuando, por un lado, como catalizadores del proceso de donación en el centro hospitalario y, por otro, difundiendo en la población el mensaje de la donación.

\section{Conclusiones}

En resumen, Andalucía ha sabido superar su clara desventaja inicial de pasados años, y ha pasado de estar en el furgón de cola a ser una comunidad de primera línea en el contexto español. Y ya sabemos que, desde hace años y de forma continuada, España está a la cabeza del mundo en donación y trasplantes. Por lo tanto, se ha conseguido mucho y en poco tiempo, y ahora las personas andaluzas trasplantadas gozan de una situación excelente.

Por todo lo anterior, la Organización Nacional de Trasplantes (ONT) ha otorgado en el pasado mes de octubre un doble reconocimiento a Andalucía por su contribución al sistema español de donación y trasplantes, premios que fueron entregados por la
Reina de España. En el XXV aniversario de esta organización, se ha querido destacar la labor de todas aquellas instituciones y equipos que más han contribuido con sus esfuerzos para mejorar los resultados y alcanzar los objetivos comunes de un programa que es referencia en todo el mundo. Es el caso de Andalucía, que ha registrado el mayor aumento en el número absoluto de donantes desde la creación de la ONT en 1989 y ha sido la comunidad que más ha contribuido a desarrollar los planes nacionales de médula ósea y de cordón umbilical.

En estos 26 años, y hasta el 31 de diciembre de 2014, han sido 5.341 las donaciones que se han producido en Andalucía, periodo en el que se han hecho 14.184 trasplantes de órganos y más de 35.000 implantes de las distintas modalidades de tejidos en los hospitales públicos autorizados para este tipo de intervenciones. Se han prácticamente triplicado las cifras de 1991 tanto en donación como en trasplantes, al igual que la tasa de donantes por millón, permitiendo superar a otras grandes comunidades, como Madrid, Cataluña o Valencia. Si Andalucía partía, al principio de la creación de la ONT, con una tasa de 11,5 donantes por millón de habitantes, ahora con la cifra de 37,5 supera ligeramente la media española $(36,0)$ y duplica las medias anuales alcanzadas por los países de la Unión Europea (19 donantes por millón), y es superior también a la de Estados Unidos (26 por millón) (Figuras 2 y 3 ).

No se puede terminar dando la sensación de triunfalismo y complacencia con lo que ya está hecho. Ni mucho menos. Estamos contentos, pero no satisfechos. Aunque la aceptación de nuestra sociedad a la donación se ha incrementado de

Figura 2.
Evolución de la donación en España desde la creación de la ONT-CCAA

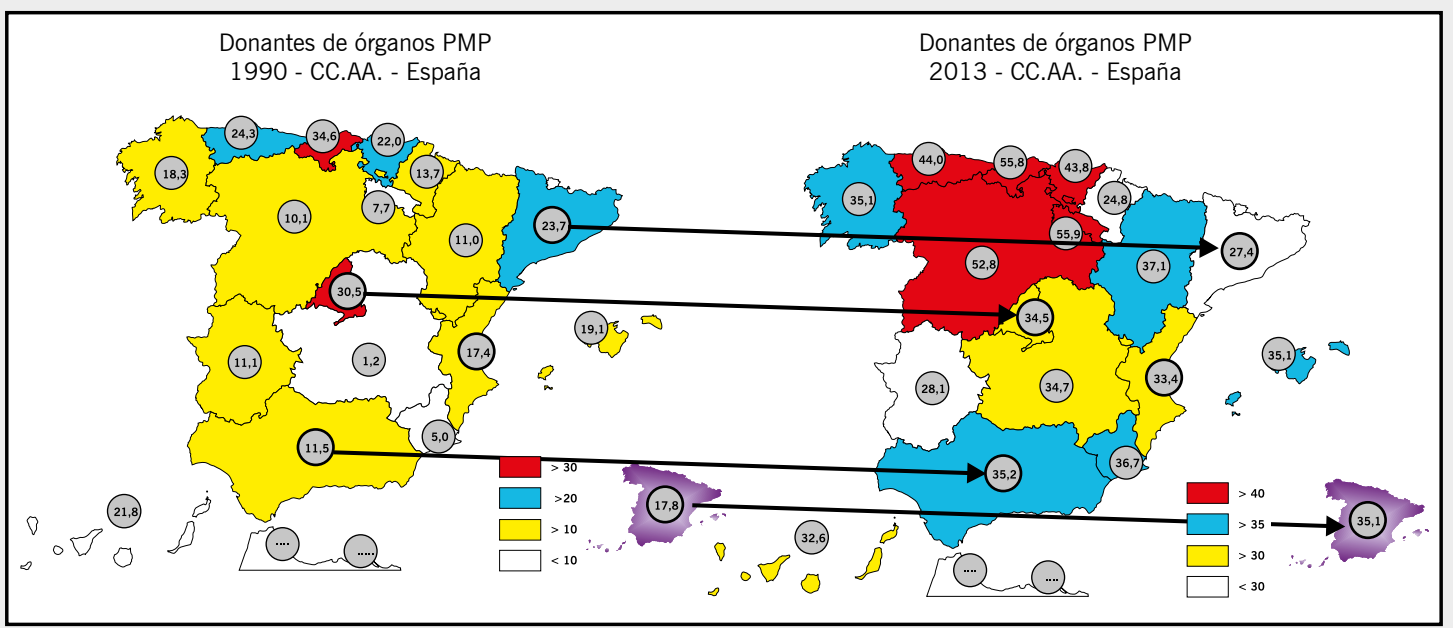




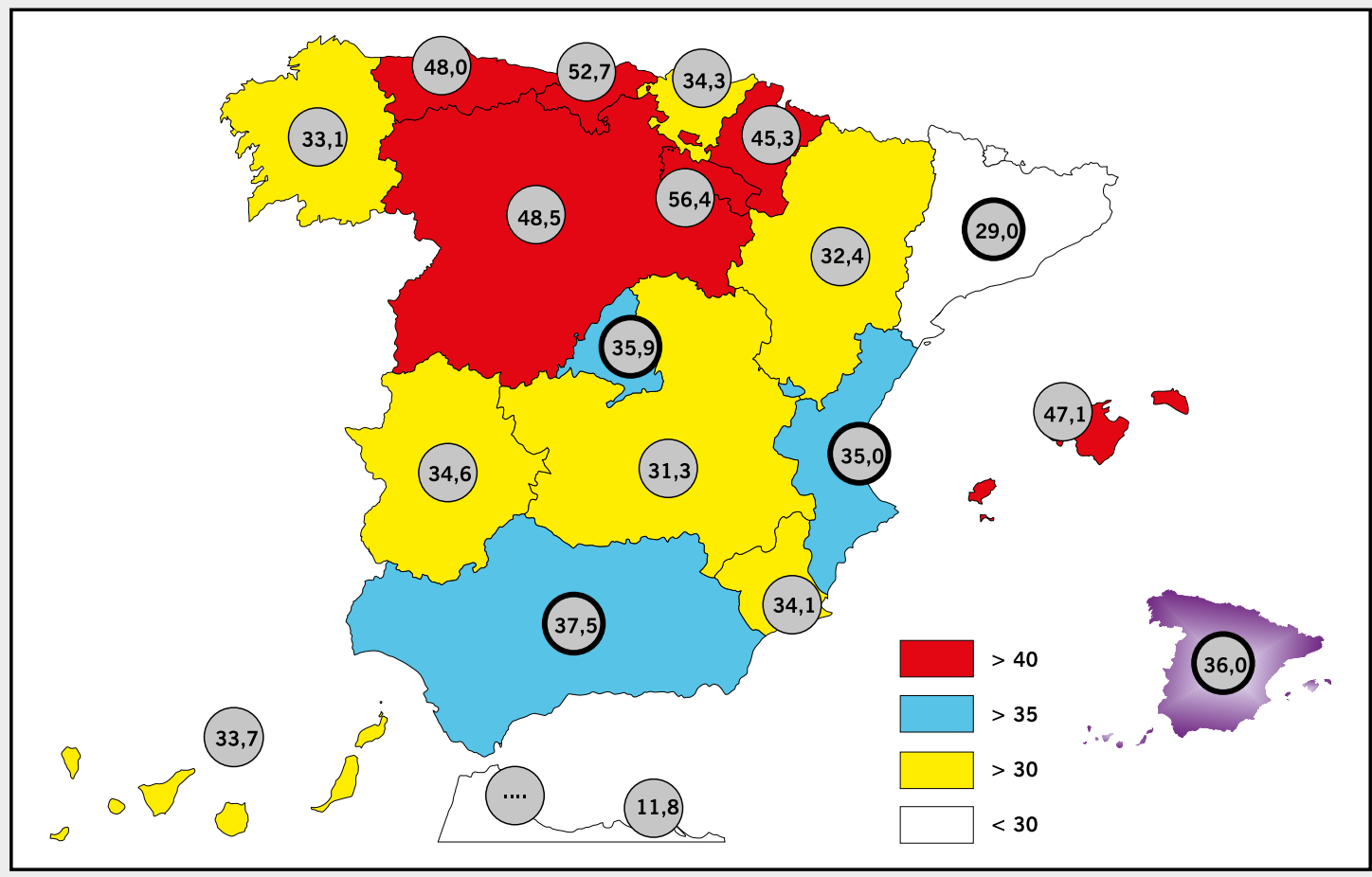

Figura 3.

Donantes de órganos PMP. 2014 por Comunidad Autónoma

forma considerable, consideramos que es posible y necesario seguir mejorándola para facilitar aún más el acceso al trasplante de los pacientes que lo necesitan. Todavía fallecen pacientes en lista de espera. Es nuestro objetivo seguir avanzando y, por ello, además apostamos de forma decidida por la investigación en trasplantes. Actualmente existen en Andalucía diversos proyectos en marcha que, con el tiempo, darán los frutos apetecidos. Tenemos que seguir estudiando y aprendiendo de nuestra experiencia para conseguir cada vez mejores resultados. Por tanto, no se trata simplemente de hacer más y más trasplantes, como si de un récord olímpico se tratara, sino de garantizar a nuestros ciudadanos las mayores posibilidades de acceso equitativo a una terapéutica perfectamente consolidada en Andalucía con los mejores resultados posibles. Todos los andaluces nos debemos sentir orgullosos y felicitarnos por los importantes avances alcanzados en el sistema de trasplantes de nuestra comunidad, y es nuestra responsabilidad seguir trabajando en esta apuesta decidida por la equidad y la calidad en los trasplantes que nos ha llevado a ser líderes mundiales.

Los excelentes resultados que estamos obteniendo no se podrían poner de manifiesto sin la generosidad de nuestra sociedad. Sin donantes no hay trasplantes. Para los profesionales que nos dedicamos a la coordinación de trasplantes y que tenemos contacto con las familias de los donantes, la donación de órganos nos resulta una acción maravillosa, humana y tan cargada de altruismo que no queremos dejar escapar ni una oportunidad para agradecer a los donantes y sus familiares el acto de la donación, verdadero desprendimiento anónimo y gratuito de algo muy apreciado pero, desgraciadamente, ya innecesario cuando la muerte señala el final de la vida.

Los autores declaran no tener ningún conflicto de intereses. 


\section{Bibliografía}

1. Ley Española sobre extracción y trasplante de órganos. 30/1979 de 27 de Octubre. BOE 6/11/79.

2. Alonso M. La labor del coordinador autonómico de trasplantes. En: Matesanz R, editor. El modelo español. Madrid: Aula Médica; 2008. p. 53-61.

3. Gentil MA, Pérez-Valdivia MA, Rodríguez-Benot A, Sola E, Osuna A, Mazuecos MA, et al. Renal transplant register of Andalusia, 2010 report. Survival in relation to the factors employed in recipient selection. Transplantation Proceedings. 2010;42(8):3130-3.
4. Castro P, Alonso M. Informe 2013 del subsistema de insuficiencia renal crónica. Servicio Andaluz de Salud. Consejería de Salud. Junta de Andalucía; 2014

5. Hernández D, Castro P, Muriel A, Ruiz-Esteban P, Alonso $M$. Mortalidad en lista de espera para trasplante renal. Nefrología. 2015;35(1):18-27.

6. Alonso M, Frutos MA, Linares A, Martín JJ, Pozo F. Micro-costing in kidney transplants. An activity based costing methodology (ABC). Trasplantation Proceedings. 2004;36(10s):633S. 